\title{
The Effect of Grain Size on the Strength of a Ti-7.4 at \% Al Alloy at Low Temperatures
}

\author{
By K. Okazaki*, T. Itoh** and H. Conrad***
}

\begin{abstract}
The effect of grain size ( 1 to $12 \mu \mathrm{m}$ ) on the deformation kinetics in a Ti-7.4 at \%Al alloy was investigated over the temperature range of 77 to $700^{\circ} \mathrm{K}$. It was found that grain size primarily influences the athermal component of the flow stress, the thermal component being independent of grain size and the same as that of unalloyed titanium of the same interstitial solute content. The deformation kinetics obey an Arrhenius-type rate equation with a Gibbs free energy of activation at $\sigma^{*}=0$ and $0^{\circ} \mathrm{K}$ equal to $\sim 1.4 \mathrm{eV}\left(\sim 0.2 \mu_{0} \mathrm{~b}^{3}\right)$. It was concluded the thermal activation parameters for the plastic deformation of the alloy are the same as those of unalloyed titanium and the rate controlling mechanism is the thermally activated overcoming of interstitial solute atoms by moving dislocations.
\end{abstract}

(Received June 8, 1973)

\section{Introduction}

Previous work ${ }^{(1)}$ has indicated that the tensile flow stress of a Ti-7.4 at \% Al alloy with the grain size of 2 $\mu \mathrm{m}$ at low temperatures $\left(T<0.4 T_{m}\right)$ is given by

$$
\sigma=\sigma^{*}\left(T, \dot{\varepsilon}, C_{i}\right)+\sigma_{\mu}\left(\mu, \varepsilon, C_{i}, C_{s}\right)
$$

where $\sigma^{*}$ is the thermal component of the flow stress, which is sensitively dependent on the temperature $T$, strain rate $\dot{\varepsilon}$ and interstitial solute content $C_{i}$, and $\sigma_{\mu}$ is the athermal component which is proportional to the modulus $\mu$ and is dependent on strain $\varepsilon$, substitutional solute content $C_{s}$ and weakly on interstitial solute content and also on grain size $d$. The thermal component of the flow stress in this alloy reflects the thermally activated overcoming of interstitial obstacles by the moving dislocations, the dislocationobstacle interaction being characterized by a Gibbs free energy of activation $\Delta G$ of approximately $1.4 \mathrm{eV}$, a maximum force of interaction $f_{i}^{*}$ of about $80 \times 10^{-6}$ dynes and an activation distance $x^{*}$ where the force first rises rapidly of about $2 b$. The effect of aluminium on the athermal component at $0.2 \%$ strain increases with the square of the concentration. And it has been also suggested that the strengthening is due to the presence of short-range order.

Generally the grain size influences the athermal component of the flow stress. This paper thus covers the effect of grain size on the strength of the same material as that of the previous work ${ }^{(1)}$ as the following-up.

\section{Experimental Procedures}

\section{Material}

The material (Ti-7.4 at \% $\mathrm{Al}$ ) employed in this investigation is the same as that used in the earlier stress relaxation studies ${ }^{(2)}$ and strain rate cycling tests ${ }^{(1)}$. It was prepared by Battelle from the same batch of titanium as that employed in the previous study of unalloyed titanium ${ }^{(3)(4)}$ and has the interstitial solute and iron contents given in Table 1. The oxygen equivalent ${ }^{(5)}$ of the total interstitial solute concentration in the alloy is 0.23 at \%; the aluminium concentration is 7.4 at \%.

The as-received rods of $6 \mathrm{~mm}$ diameter were swaged at room temperature without any intermediate annealing to $1.7 \mathrm{~mm}$ diameter wires, representing a reduction in area of $93 \%$. Tensile specimens $50 \mathrm{~mm}$ long were cut from the swaged wire for testing and chemically polished to $1.6 \mathrm{~mm}$ diameter in a solution consisting of $70 \%$ by volume $\mathrm{HNO}_{3}$ and $30 \%$ by volume HF, following which they were rinsed well in running water and dried in air after dipping in ethyl

Table 1 Chemical composition of the Battelle materials. (ppm by weight)

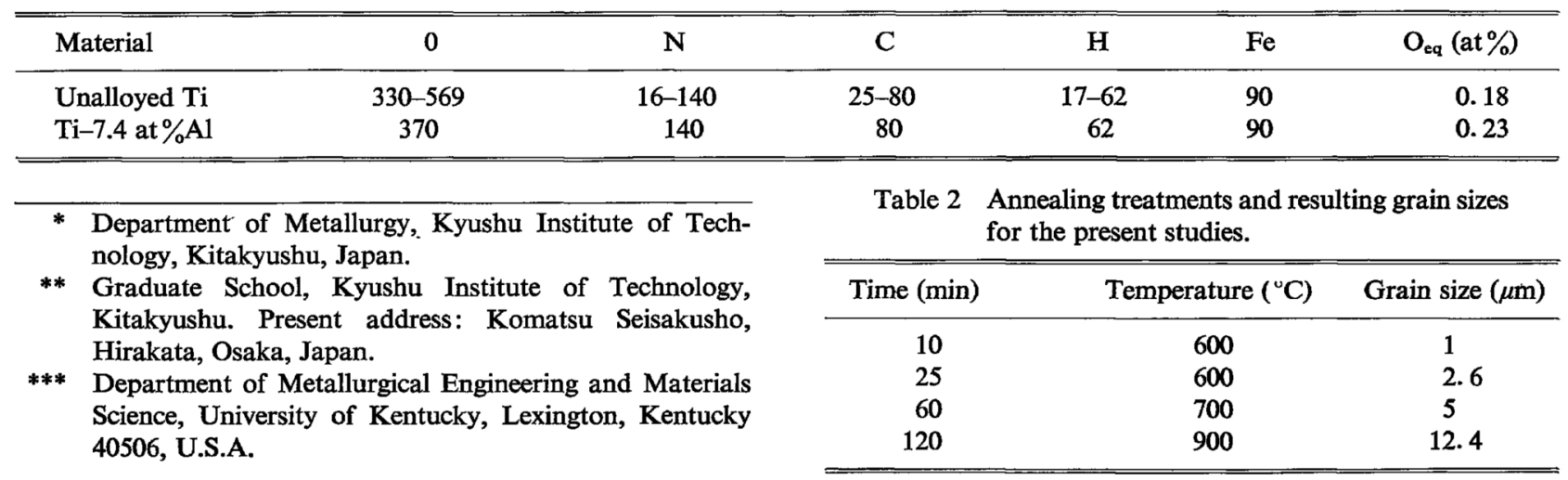

Trans. JIM 
alcohol. They were then annealed in a vacuum of less than $10^{-6}$ torr for various times at various temperatures to yield grain sizes of 1 to $12 \mu \mathrm{m}$ (see Table 2). The grain sizes were determined by optical microscopy using the mean linear intercept method. The grain size distribution and texture of the alloy ${ }^{(6)}$ are very similar to those of the unalloyed Battelle material of the same origin and grain size ${ }^{(7)}$. Thus, except for the aluminium content, the present alloy is essentially the same as the unalloyed Battelle titanium employed in the previous study ${ }^{(3)(4)}$.

\section{Mechanical testing}

The wire tensile specimens were gripped in clamptype grips, yielding a gauge length of $25 \mathrm{~mm}$, and tested in an Instron-type, Shimadzu IS-500 tensile testing machine. Two types of tests were performed over the temperature range of 77 to $700^{\circ} \mathrm{K}$ : (a) simple tension tests in which the strain rate was maintained constant at a nominal value of $3.3 \times 10^{-4} \mathrm{sec}^{-1}$ throughout the test to fracture and (b) strain rate cycling tests in which the strain rate was cycled at a ratio of $5: 1$, starting from the base strain rate of $3.3 \times 10^{-4} \mathrm{sec}^{-1}$, about every $2 \%$ of the true plastic strain. The load sensitivity was $20 \mathrm{~g}$ and the elongation measured from the crosshead of the testing machine was accurate to about $2.5 \times 10^{-3} \mathrm{~mm}$ (approximately $10^{-4}$ strain). The test temperatures were controlled within $2^{\circ} \mathrm{K}$ using baths containing liquid nitrogen $\left(77^{\circ} \mathrm{K}\right)$, dry-ice and acetone $\left(200^{\circ} \mathrm{K}\right)$, ambient air $\left(300^{\circ} \mathrm{K}\right)$, silicone oil $\left(400\right.$ and $\left.500^{\circ} \mathrm{K}\right)$, and fused sodium nitrate $\left(600\right.$ and $\left.700^{\circ} \mathrm{K}\right)$.

\section{Experimental Results}

Typical true stress-strain curves for $5 \mu \mathrm{m}$ grain size as a function of temperature are illustrated in Fig. 1. It

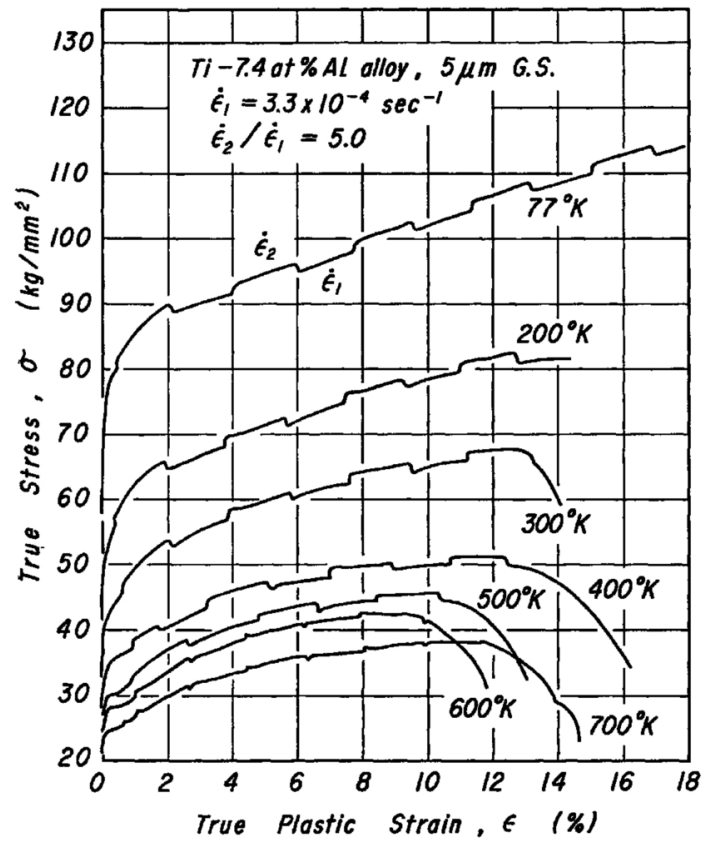

Fig. 1 True stress versus true strain curves with strain rate cycling as a function of temperature for a $\mathrm{Ti}-7.4$ at $\% \mathrm{Al}$ alloy of $5 \mu \mathrm{m}$ grain size. was found that the strain rate cycling did not alter the form of the stress-strain curves when compared with the test conducted at a single strain rate. After about $2 \%$ strain, stress strain curves of the alloy are approximately linear at the lowest temperature $\left(77^{\circ} \mathrm{K}\right)$ and become more nearly parabolic at higher temperatures. The stress-strain behavior for other grain sizes are similar to those shown here for $5 \mu \mathrm{m}$ grain size. The values of true stress, true plastic strain and ductility of the alloy tested at $3.3 \times 10^{-4} \mathrm{sec}^{-1}$ strain rate are listed in Table 3.

The effect of temperature on the stress at proportional limit for various grain sizes are depicted in Fig. 2 , where the curves at various strains for $1 \mu \mathrm{m}$ grain size are also shown as an example. It is seen in this figure that all the curves are nearly parallel to each other and the variation of grain size and plastic strain do not alter the stress-strain behavior.

Figure 3 shows the grain size dependence of the

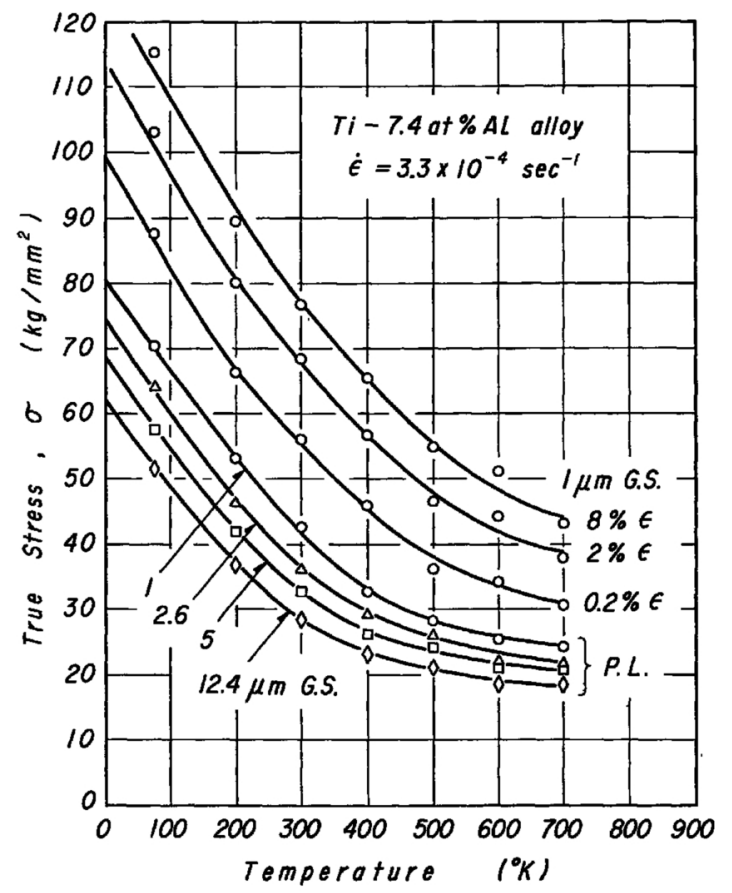

Fig. 2 Flow stress versus temperature with grain size and plastic strain as the parameters for a $\mathrm{Ti}-7.4$ at $\% \mathrm{Al}$ alloy.

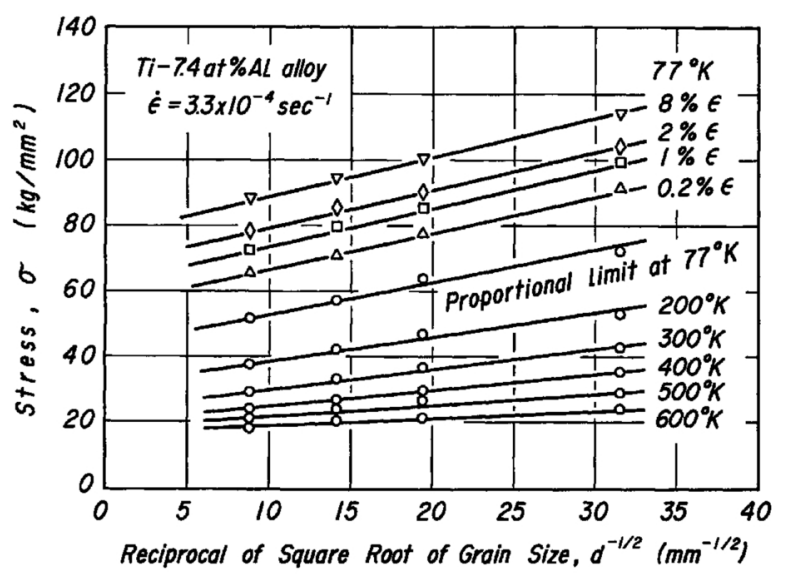

Fig. 3 Stress versus the reciprocal of square root of grain size with strain and temperature as the parameters for a $\mathrm{Ti}-7.4$ at $\% \mathrm{Al}$ alloy. 
Table 3 True stress, true plastic strain and ductility for $\mathrm{Ti}-4 \% \mathrm{Al}$ tested at the strain rate of $3.3 \times 10^{-4}$ per sec.

\begin{tabular}{|c|c|c|c|c|c|c|c|}
\hline & \multicolumn{7}{|c|}{ Temperature $\left({ }^{\circ} \mathbf{K}\right)$} \\
\hline & 77 & 200 & 300 & 400 & 500 & 600 & 700 \\
\hline Strain $(\%)$ & \multicolumn{7}{|c|}{ Stress $\left(\mathrm{kg} / \mathrm{mm}^{2}\right)$} \\
\hline \multicolumn{8}{|l|}{$1 \mu \mathrm{m}$ G.S. } \\
\hline P.L. & 70.7 & 53.3 & 42.8 & 32.8 & 28.4 & 25.4 & 24.0 \\
\hline 0.2 & 87.6 & 66.5 & 56.2 & 46.0 & 36.3 & 34.2 & 30.8 \\
\hline 0.5 & 93.7 & 71.8 & 60.7 & 49.2 & 39.5 & 37.4 & 33.5 \\
\hline 1.0 & 98.7 & 76.3 & 64.8 & 53.7 & 42.7 & 40.5 & 35.5 \\
\hline 2.0 & 103.5 & 80.2 & 68.4 & 57.9 & 46.6 & 44.4 & 37.7 \\
\hline 4.0 & 108.0 & 83.8 & 72.2 & 62.0 & 50.7 & 48.0 & 40.6 \\
\hline 8.0 & 115.2 & 89.5 & 76.8 & 65.8 & 54.9 & 51.3 & 43. 1 \\
\hline UTS & - & - & 79.0 & 67.4 & 55.6 & 51.4 & 44.6 \\
\hline$e_{f}(\%)$ & 16.6 & 12.4 & 14.0 & 10.4 & 12.7 & 13.1 & 21.2 \\
\hline \multicolumn{8}{|c|}{$2.6 \mu \mathrm{m}$ G.S. } \\
\hline P.L. & 64.2 & 46.5 & 36.3 & 29.7 & 26.2 & 21.9 & 21.7 \\
\hline 0.2 & 77.5 & 59.1 & 47.6 & 40.0 & 32.2 & 29.0 & 26.7 \\
\hline 0.5 & 81.8 & 61.8 & 51.2 & 43.5 & 33.0 & 31.7 & 28.2 \\
\hline 1.0 & 85.8 & 64.2 & 54.4 & 46.0 & 34.9 & 33.6 & 30.0 \\
\hline 2.0 & 89.9 & 70.3 & 57.4 & 50.0 & 38.1 & 37.1 & 32.2 \\
\hline 4.0 & 93.3 & 74.0 & 61.8 & 53.1 & 42.4 & 41.4 & 35.6 \\
\hline 8.0 & 100.3 & 79.9 & 65.2 & 58.3 & 46.4 & 43.4 & 38.8 \\
\hline UTS & 117.0 & 81.9 & 67.5 & 61.8 & 47.9 & 46.3 & 33.9 \\
\hline$e_{f}(\%)$ & 19.4 & 16.1 & 13.6 & 14.7 & 12.9 & 14.4 & 13.9 \\
\hline \multicolumn{8}{|l|}{$5 \mu \mathrm{m}$ G.S. } \\
\hline P.L. & 57.6 & 41.9 & 32.9 & 26.3 & 24.3 & 21.3 & 20.6 \\
\hline 0.2 & 71.5 & 53.7 & 42.6 & 34.8 & 30.4 & 26.0 & 24.6 \\
\hline 0.5 & 76.0 & 56.5 & 45.2 & 35.8 & 30.3 & 25.8 & 24.8 \\
\hline 1.0 & 79.5 & 60.7 & 48.1 & 38.2 & 32.4 & 27.3 & 26.8 \\
\hline 2.0 & 85.4 & 64.4 & 52.3 & 42.6 & 36.2 & 30.9 & 29.7 \\
\hline 4.0 & 88.0 & 68.5 & 57.2 & 46.8 & 40.4 & 34.9 & 33.4 \\
\hline 8.0 & 95.4 & 75.5 & 63.0 & 48.6 & 44.3 & 37.5 & 36.8 \\
\hline UTS & 114.2 & 81.7 & 66.5 & 52.1 & 45.0 & 37.6 & 38.0 \\
\hline$e_{f}(\%)$ & 20.3 & 14.3 & 14.2 & 16.3 & 13.2 & 12.5 & 14.8 \\
\hline \multicolumn{8}{|c|}{ 12. $4 \mu \mathrm{m}$ G.S. } \\
\hline P.L. & 51.6 & 36.7 & 28.6 & 23.2 & 21.3 & 18.5 & 18.5 \\
\hline 0.2 & 66.0 & 46.8 & 37.5 & 31.2 & 26.0 & 22.8 & 21.6 \\
\hline 0.5 & 69.4 & 50.7 & 39.0 & 33.7 & 28.4 & 24.7 & 23.7 \\
\hline 1.0 & 72.0 & 54.7 & 42.6 & 35.5 & 31.3 & 26.9 & 25.9 \\
\hline 2.0 & 78.3 & 58.4 & 46.4 & 39.5 & 35.4 & 29.7 & 29.0 \\
\hline 4.0 & 81.5 & 62.8 & 50.1 & 44.6 & 39.5 & 32.7 & 32.8 \\
\hline 8.0 & 88.5 & 69.2 & 54.3 & 47.8 & 43.2 & 33.9 & 35.2 \\
\hline UTS & 110.1 & 76.2 & 54.6 & 48.2 & 43.6 & 34.5 & 35.4 \\
\hline$e_{f}(\%)$ & 23.6 & 17.0 & 11.0 & 15.4 & 11.8 & 12.0 & 12.5 \\
\hline
\end{tabular}

Table 4 The values of Hall-Petch constant $K$ and $\sigma_{i}$ in a Ti-7.4 at \%Al alloy.

\begin{tabular}{|c|c|c|c|c|c|c|c|c|}
\hline \multicolumn{2}{|c|}{ Temp. $\left({ }^{\circ} \mathbf{K}\right)$} & \multirow{2}{*}{$\frac{\text { P.L. }}{0.831}$} & \multirow{2}{*}{$\frac{0.2 \% \varepsilon}{0.950}$} & \multirow{2}{*}{$\frac{1 \% \varepsilon}{1.061}$} & \multirow{2}{*}{$\frac{2 \% \varepsilon}{1.090}$} & \multirow{3}{*}{$\begin{array}{l}8 \% \varepsilon \\
1.6163 \\
78.2\end{array}$} & \multirow{3}{*}{$\frac{\bar{K}}{1.066}$} & \multirow{3}{*}{$\frac{\bar{K} / \mu \times 10^{-4}}{1.95}$} \\
\hline 77 & $K$ & & & & & & & \\
\hline & $\sigma_{i}$ & 45.6 & 58.0 & 62.4 & 69.0 & & & \\
\hline \multirow[t]{2}{*}{200} & $K$ & 0.718 & 0.843 & 0.935 & 0.942 & 0.874 & 0.899 & 1.75 \\
\hline & $\sigma_{i}$ & 31.3 & 40.9 & 46.6 & 50.9 & 62.3 & & \\
\hline \multirow[t]{2}{*}{300} & $K$ & 0.614 & 0.817 & 0.978 & 0.960 & 0.939 & 0.924 & 1.91 \\
\hline & $\sigma_{i}$ & 23.7 & 30.8 & 34.3 & 38.3 & 47.3 & & \\
\hline \multirow[t]{2}{*}{400} & $K$ & 0.417 & 0.657 & 0.833 & 0.836 & 0.854 & 0.795 & 1.75 \\
\hline & $\sigma_{i}$ & 20.3 & 25.8 & 27.9 & 32.0 & 39.2 & & \\
\hline \multirow[t]{2}{*}{500} & $K$ & 0.297 & 0.428 & 0.520 & 0.513 & 0.533 & 0.499 & 1.17 \\
\hline & $\sigma_{i}$ & 19.5 & 23.3 & 25.6 & 29.5 & 37.3 & & \\
\hline \multirow[t]{2}{*}{600} & $K$ & 0.286 & 0.497 & 0.644 & 0.684 & 0.779 & 0.651 & 1.64 \\
\hline & $\sigma_{i}$ & 16.5 & 18.7 & 20.1 & 22.8 & 27.0 & & \\
\hline
\end{tabular}




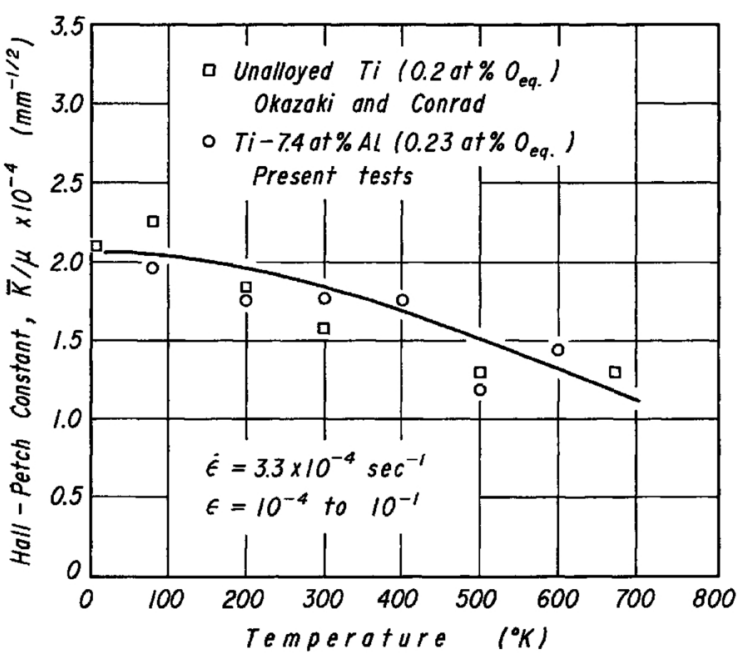

Fig. 4 Hall-Petch constant $\bar{K} / \mu$ versus temperature for a $\mathrm{Ti}-7.4$ at $\% \mathrm{Al}$ alloy and unalloyed titanium.

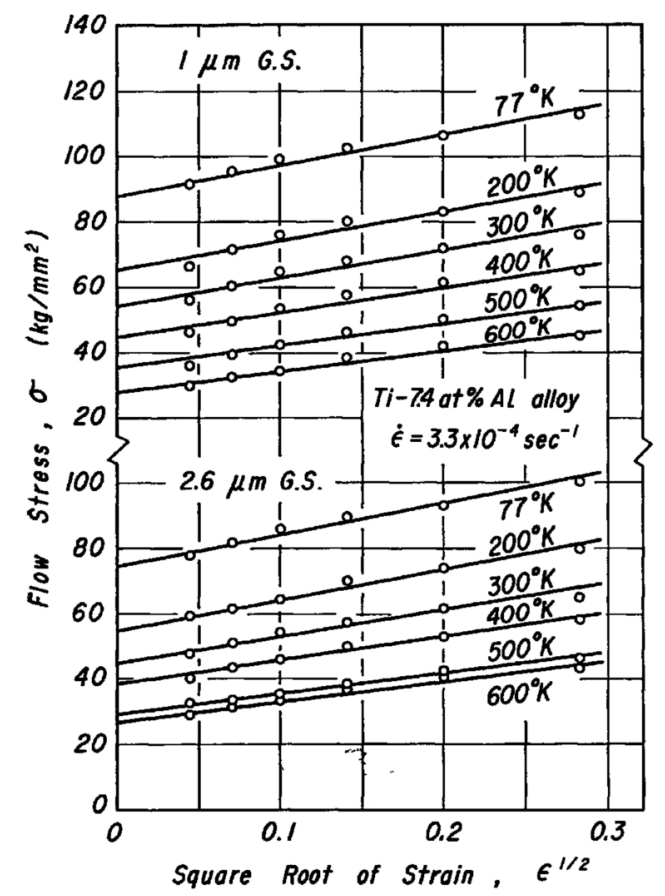

Fig. 5(a) Effect of strain on the flow stress of a Ti-7.4 at $\% \mathrm{Al}$ of 1 and $2.6 \mu \mathrm{m}$ grain sizes as a function of temperature.

stress at proportional limit for the alloy as a function of temperature, where the effect of plastic strain on the stress-grain size relationship is also shown at $77^{\circ} \mathrm{K}$. The Hall-Petch relationship holds for all temperatures and strains:

$$
\sigma=\sigma_{i}+K d^{-1 / 2}
$$

where $\sigma_{i}$ is the intercept at $d^{-1 / 2}=0$ and $K$ a constant. Both $\sigma_{i}$ and $K$ decrease with increasing deformation temperature. Previous work on unalloyed titanium ${ }^{(4)}$ has shown that the Hall-Petch constant $K$ given by the slope of the straight lines is relatively independent of strain and interstitial solute content. However, as given in Table 4, the $K$ value of the alloy increases gradually with increasing strain. Depicted in Fig. 4 is the effect of temperature on the average value of $K$ for strains up to $8 \%$ divided by the shear modulus $\mu$
( $\simeq 3 / 8 E$, where $E$ is Young's modulus) derived ${ }^{(8)}$ from the elastic constants of Fisher and Renken ${ }^{(9)}$. The reason for this choice of the average polycrystalline shear modulus $\mu$ rather than $C_{66}$ used previously ${ }^{(4)}$ is discussed elsewhere ${ }^{(1)}$. It is seen that $\bar{K} / \mu$ decreases only slightly with temperature. For comparison, the data on unalloyed titanium ${ }^{(4)}$ are also plotted together, and thus the addition of aluminium to titanium appears not to influence the temperature dependence of $\bar{K} / \mu$.

Figures 5(a) and 5(b) show that the flow stress varies in an approximately linear fashion with the square root of the strain yielding

$$
\sigma \simeq \sigma_{0}+h \varepsilon^{1 / 2}
$$

where $\sigma_{0}$ is the intercept at zero strain $(\varepsilon=0)$ and $h$ the strain hardening coefficient. A strong effect of grain size and temperature on the intercept $\sigma_{0}$ is evident. On the other hand, the strain hardening coefficient

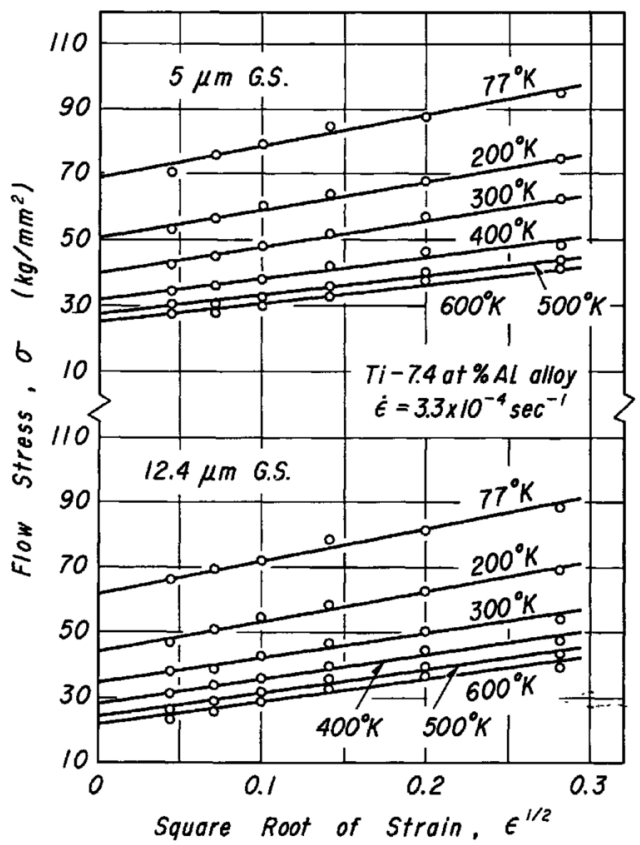

Fig. 5(b) Effect of strain on the flow stress of a Ti-7.4 at $\% \mathrm{Al}$ of 5 and $12.4 \mu \mathrm{m}$ grain sizes as a function of temperature.

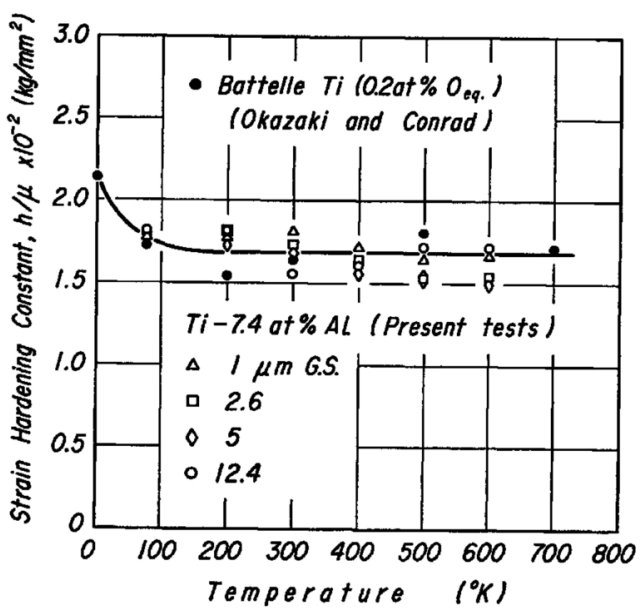

Fig. 6 Effect of temperature on the strain hardening constant $h / \mu$ for a Ti-7.4 at \%Al alloy of various grain sizes and unalloyed titanium. 
divided by modulus, $h / \mu$ is essentially independent of temperature and grain size and also aluminium addition to titanium; see Fig. 6.

Single strain rate cycling tests were performed by changing the strain rate by a factor of five from $\dot{\varepsilon}_{1}$ to $\dot{\varepsilon}_{2}$ and vice versa with a base strain rate of $3.3 \times 10^{-4}$ $\mathrm{sec}^{-1}$ over the temperature range of 77 to $700^{\circ} \mathrm{K}$. For a given material and test temperature, the change in flow stress $\Delta \sigma$ associated with the 5: 1 change in strain rate was relatively independent of the direction of the rate change, grain size and the strain; see Fig. 7 . When significant yield points (positive for a stress increase and negative for a stress decrease) occurred, the difference between $\Delta \sigma_{p}$ (peak value) and $\Delta \sigma_{e}$ (extrapolated value) became appreciable. It was felt better to take $\Delta \sigma_{p}$ as being representative of a constant dislocation structure before and after the strain rate change. Evident in the figure is that the change in stress is essentially independent of the grain size and plastic strain, but varies with temperature. Figure 8 shows the variation of the reciprocal of the strain rate sensitivity $1 / \beta$ (where $\beta$ is given by $\Delta \ln \dot{\varepsilon} / \Delta \sigma_{p}$ ) plotted against temperature. The data of unalloyed titanium $^{(4)(10)}$ are also plotted in the figure, where the

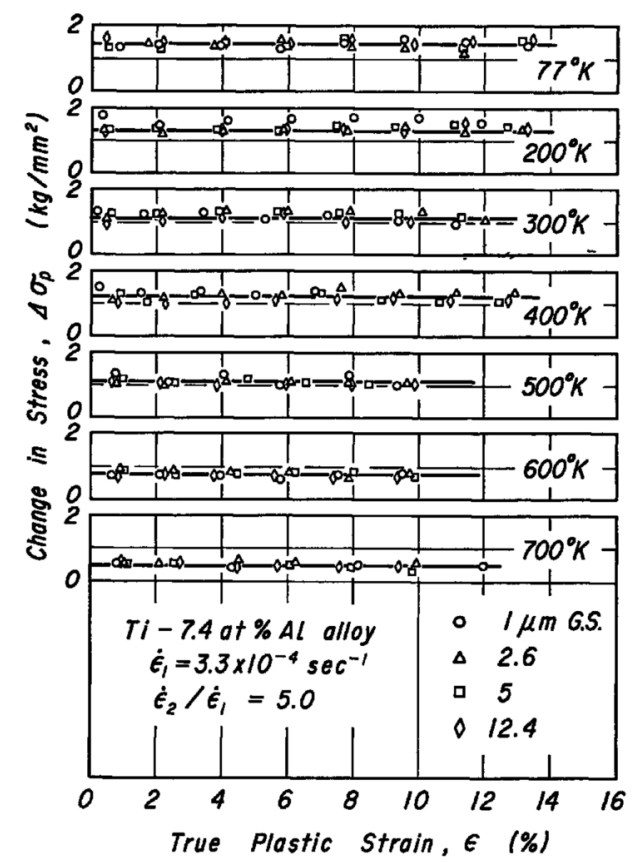

Fig. 7 The change in stress associated with a 5:1 change in strain rate as function of grain size and temperature for $\mathrm{a} \mathrm{Ti}-7.4$ at $\% \mathrm{Al}$ alloy. addition of aluminium does not alter the behavior.

In order to establish the reference temperature $T_{0}$ where the flow stress first becomes insensitive to temperature, the flow stress at $0.2 \%$ strain is plotted against the square root of temperature in Fig. 9, where straight lines can be drawn through the data points in the low temperature region below $530^{\circ} \mathrm{K}$ and at this temperature sharp inflection points are observed for all the grain sizes. As seen from Fig. 2, the temperature dependence of the flow stress of the alloy is relatively independent of strain. Also, it is not very different

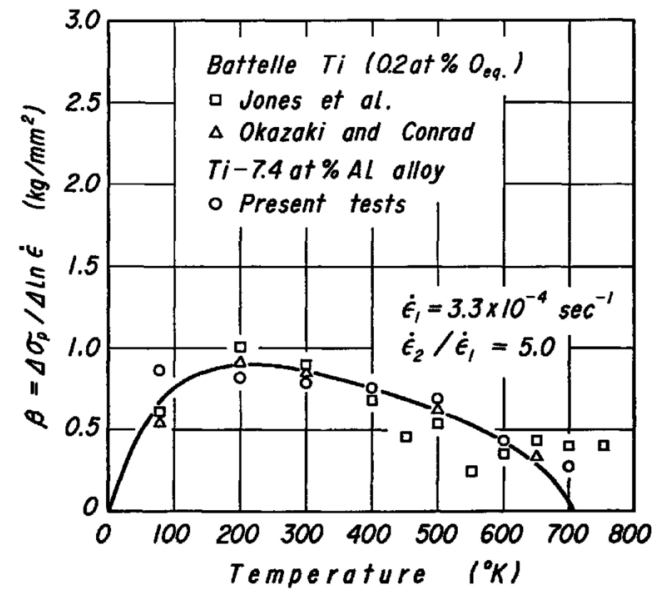

Fig. 8 Effect of temperature on the strain rate sensitivity of the flow stress for a Ti-7.4 at \%Al allay and unalloyed titanium.

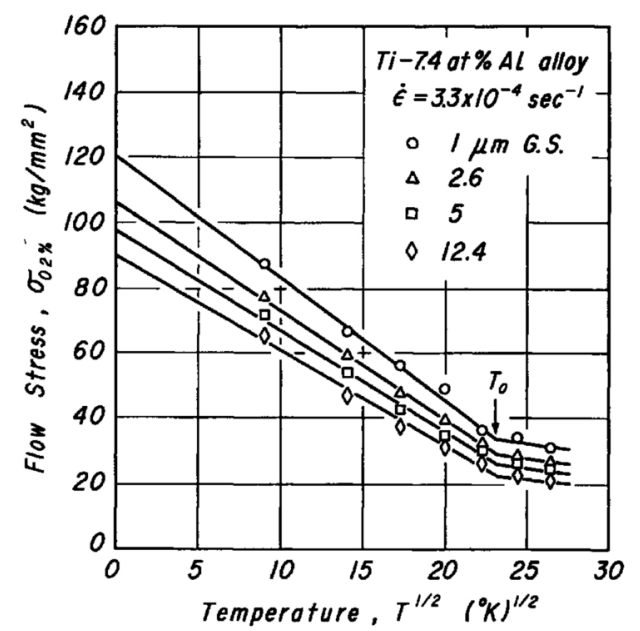

Fig. 9 Flow stress at $0.2 \%$ strain versus the square root of temperature as a function of grain size for a $\mathrm{Ti}-7.4$ at $\% \mathrm{Al}$ alloy.

Table 5 The values of strain hardening coefficient $h\left(\mathrm{~kg} / \mathrm{mm}^{2}\right)$ and $h / \mu$ for a Ti-7.4 at $\% \mathrm{Al}$ alloy.

\begin{tabular}{|c|c|c|c|c|c|c|c|c|}
\hline \multicolumn{2}{|c|}{ G.S. $(\mu \mathrm{m})$} & \multirow{2}{*}{$\begin{array}{c}77^{\circ} \mathrm{K} \\
96.7 \\
1.76\end{array}$} & \multirow{2}{*}{$\begin{array}{c}200^{\circ} \mathrm{K} \\
91.7 \\
1.79\end{array}$} & \multirow{2}{*}{$\begin{array}{c}300^{\circ} \mathrm{K} \\
88.3 \\
1.82\end{array}$} & \multirow{2}{*}{$\begin{array}{c}400^{\circ} \mathrm{K} \\
78.3 \\
1.72\end{array}$} & \multirow{2}{*}{$\begin{array}{c}500^{\circ} \mathrm{K} \\
70.3 \\
1.65\end{array}$} & \multirow{2}{*}{$\begin{array}{c}600^{\circ} \mathrm{K} \\
66.7 \\
1.68\end{array}$} & \multirow[b]{2}{*}{$\times 10^{-2}$} \\
\hline 1 & $\begin{array}{l}h \\
h / \mu\end{array}$ & & & & & & & \\
\hline 2.6 & $\begin{array}{l}h \\
h / \mu\end{array}$ & $\begin{array}{l}96.7 \\
1.76\end{array}$ & $\begin{array}{l}93.3 \\
1.82\end{array}$ & $\begin{array}{r}83.3 \\
1.72\end{array}$ & $\begin{array}{r}74.3 \\
1.63\end{array}$ & $\begin{array}{c}64.7 \\
1.52\end{array}$ & $\begin{array}{r}60.7 \\
1.53\end{array}$ & $\times 10^{-2}$ \\
\hline 5 & $\begin{array}{l}h \\
h / \mu\end{array}$ & $\begin{array}{l}96.7 \\
1.76\end{array}$ & $\begin{array}{r}88.7 \\
1.73\end{array}$ & $\begin{array}{c}81.7 \\
1.69\end{array}$ & $\begin{array}{r}66.7 \\
1.47\end{array}$ & $\begin{array}{c}60.0 \\
1.41\end{array}$ & $\begin{array}{c}60.0 \\
1.51\end{array}$ & $\times 10^{-2}$ \\
\hline 12.4 & $\begin{array}{l}h \\
h / \mu\end{array}$ & $\begin{array}{r}100.0 \\
1.82\end{array}$ & $\begin{array}{r}93.3 \\
1.82\end{array}$ & $\begin{array}{c}75.0 \\
1.55\end{array}$ & $\begin{array}{r}73.7 \\
1.62\end{array}$ & $\begin{array}{r}73.3 \\
1.72\end{array}$ & $\begin{array}{r}68.0 \\
1.72\end{array}$ & $\times 10^{-2}$ \\
\hline
\end{tabular}


from that of the unalloyed titanium of the same interstitial content and grain size, indicating that the effect of the aluminium is primarily on the athermal component of the flow stress. In the previous work on the same alloy ${ }^{(1)}$ relatively constant values of the flow stress divided by the average polycrystalline shear modulus were obtained at temperatures of 600 and $700^{\circ} \mathrm{K}$ and it was concluded that the temperature where the flow stress first became to be the athermal component itself was $530^{\circ} \mathrm{K}$.

Since the form of the curves of Figs. 2 and 9 is in accord with eq. (1) indicating the feasibility of separating the flow stress into the two component, a thermal $\sigma^{*}$ and an athermal $\sigma_{\mu}$. The values of $\sigma^{*}$ obtained from the present data by taking

$$
\sigma_{\mu_{T}}=\sigma_{530} \mu_{T} / \mu_{530}
$$

are plotted versus the temperature in Fig. 10. Evident is that grain size does not influence the thermal component of the flow stress of the alloy.

\section{Discussion}

Assuming that a single thermally activated dislocation mechanism is rate controlling, the deformation kinetics may be described by an Arrhenius-type equation of the form

$$
\dot{\varepsilon}=\frac{\rho_{m}}{M} b \bar{v}=\frac{\rho_{m} A b}{M l^{*}}\left(\frac{b v_{D}}{l^{*}}\right) \exp (-\Delta G / k T)
$$

where $\dot{\varepsilon}$ is the strain rate, $\rho_{m}$ the mobile dislocation density, $b$ their Burgers vector, $\bar{v}$ their average velocity, $M$ the Taylor factor, $l^{*}$ the dislocation segment length involved in the thermal activation, $A$ the area of the slip plane swept out per successful thermal fluctuation, $v_{D}$ the Debye frequency and $\Delta G(=\Delta H-T \Delta S)$ the Gibbs free energy of activation.

The activation volume $V$ is derived from eq. (5) as

$$
V=-\left.\frac{\partial(\Delta G)}{\partial \sigma}\right|_{T}=k T\left(\frac{\partial \ln \dot{\varepsilon}}{\partial \sigma}\right)_{T}=k T \beta_{T} .
$$

The values of the activation volume $V$ obtained by using eq. (6) are plotted in Fig. 11 as a function of the thermal component of the flow stress $\sigma^{*}$. A curve which can be drawn through the data points for various grain sizes rises to high values at $\sigma^{*}$ equal to zero and above about $\sigma^{*}=15 \mathrm{~kg} / \mathrm{mm}^{2}$ the data can be represented by a straight line passing through $V$ equal zero at $\sigma^{*}=\sigma_{0}^{*}\left(\sigma^{*}\right.$ at $\left.0^{\circ} \mathrm{K}\right)$. Evident from the figure is that the activation volume thus derived is independent of grain size, indicating that grain size does not play a role in the thermal activation process directly and only influences the athermal component of the flow stress in the way as do the substitutional solute atoms.

For interstitial solutes in titanium, the Gibbs free energy is given by the form of ${ }^{(4)(11)}$

$$
\Delta G=Q-\alpha V \sigma+\frac{3}{2} \alpha V \sigma^{*}
$$

where
Table 6 Activation energies $\Delta G(\mathrm{eV})$ as a function of grain size and temperature.

\begin{tabular}{cccccc}
\hline \hline Grain size & & \multicolumn{4}{c}{ Temperature $\left({ }^{\circ} \mathrm{K}\right)$} \\
$(\mu \mathrm{m})$ & 77 & 200 & 300 & 400 & 500 \\
\hline 1 & 0.145 & 0.499 & 0.774 & 0936 & 1.331 \\
2.6 & 0.106 & 0.473 & 0.792 & 1.015 & 1.295 \\
5 & 0.114 & 0.467 & 0.770 & 1.072 & 1.204 \\
12.4 & 0.124 & 0.465 & 0.848 & 0.942 & 1.291 \\
\hline \hline
\end{tabular}

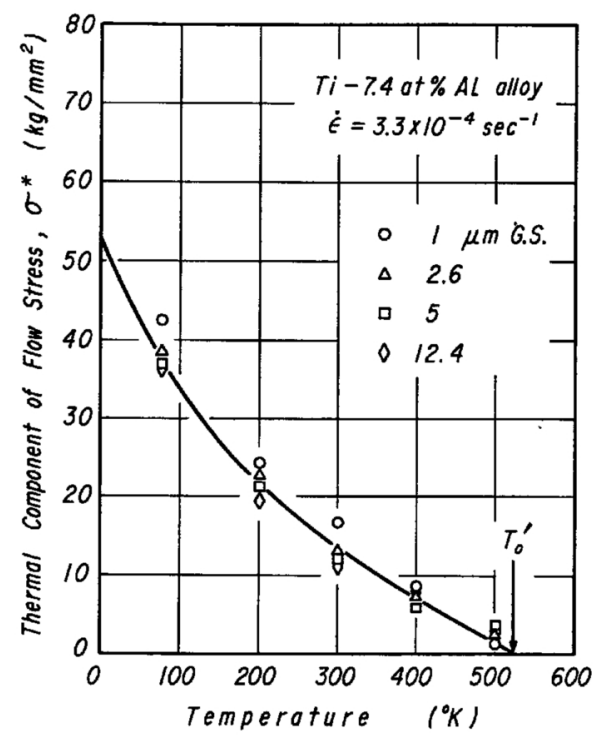

Fig. 10 Effect of temperature on the thermal component of the flow stress as a function of grain size for a $\mathrm{Ti}-7.4$ at $\% \mathrm{Al}$ alloy.

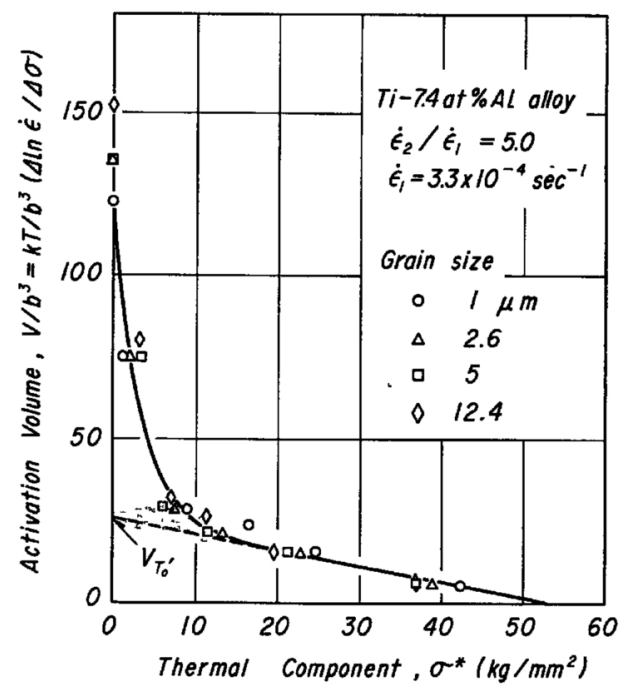

Fig. 11 Effect of the thermal component of the flow stress on the activation volume as a function of grain size for a $\mathrm{Ti}-7.4 \mathrm{at} \% \mathrm{Al}$ alloy.

$$
Q=-V T\left(\frac{\partial \sigma}{\partial T}\right)_{\dot{\varepsilon}}
$$

and

$$
\alpha=-\frac{T}{\mu} \frac{d \mu}{d T} .
$$

Moreover, rearranging eq. (5) one obtains

$$
\Delta G=k T \ln \left(\dot{\varepsilon} / \dot{\varepsilon}_{0}\right)
$$

where $\dot{\varepsilon}_{0}=\rho_{m} A b^{2} v_{D} /\left[M\left(l^{*}\right)^{2}\right]$. Thus, according to eq. 


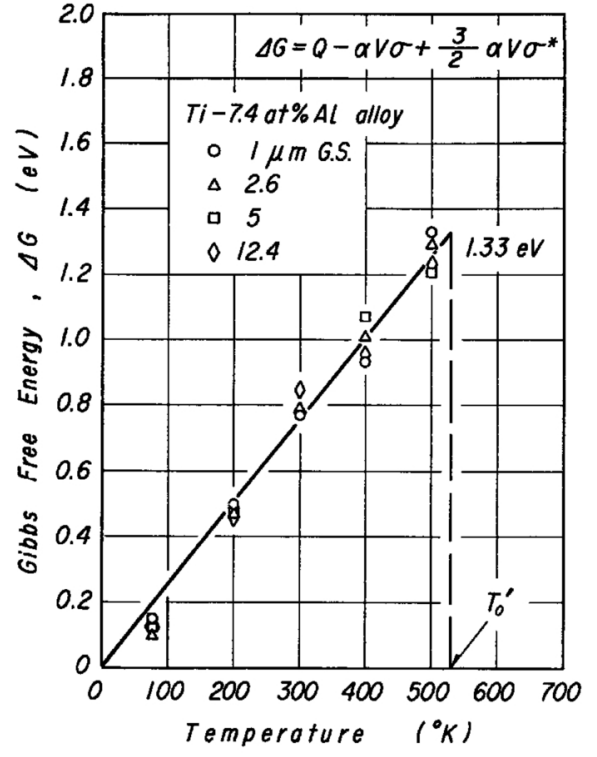

Fig. 12 Gibbs free energy versus temperature as a function of grain size for a Ti-7.4 at \% Al alloy.

(10) $\Delta G$ should be proportional to the temperature at a constant strain rate and constant $\dot{\varepsilon}_{0}$.

Values of $G$ derived from the experimental data on the alloy are plotted as a function of the temperature in Fig. 12. It is seen that the data points of various grain sizes fall on a straight line through the origin, in accord with eq. (10). Moreover, the values are in good accord with those for unalloyed titanium of various interstitial contents ${ }^{(4)}$, indicating that the rate controlling mechanism in the alloy is the same as that in unalloyed titanium, namely thermally activated overcoming of interstitial solutes by the moving dislocations.

A force-activation distance curve can be derived from the experimental data if we assume that the ratecontrolling dislocation mechanism during the plastic deformation of titanium and its alloys at low temperatures is thermally activated overcoming of interstitial solutes. The force $f *$ acting on the dislocations due to the applied stress is given by

$$
f^{*}=\tau^{*} b l^{*}
$$

where $\tau^{*}=\sigma^{*} / M$. A reasonable approximation for the effects of stress and temperature on $l^{*}$ is the Friedel relation $^{(12)}$

$$
l^{*}=\left(\frac{2 \mu b}{N \tau^{*}}\right)^{1 / 3}
$$

where $N$ is the obstacle density on the slip plane, which in alpha titanium is ${ }^{(13)}$

$$
N \simeq C_{i} / b^{2} .
$$

Combining eqs. (12) and (13) gives

$$
l^{*}=b\left(\frac{2 \mu}{\tau^{*} C_{i}}\right)^{1 / 3}
$$

Upon inserting eq. (14) into eq. (11)

$$
f^{*}=\left(\tau^{*}\right)^{2 / 3} b^{2}\left(2 \mu / C_{i}\right)^{1 / 3}=f_{i}^{*}
$$

where $f_{i}^{*}$ is the resisting force due to the obstacle.

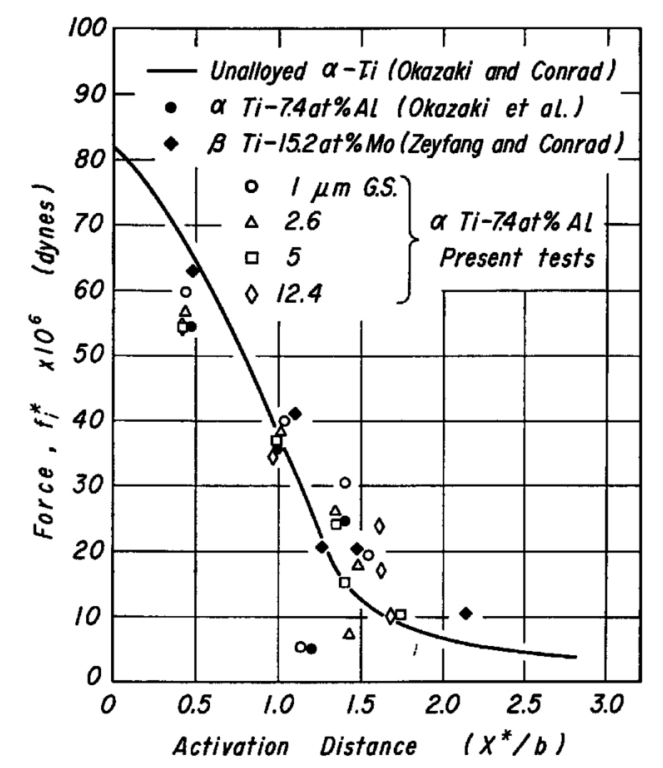

Fig. 13 Force-activation curve for the deformation kinetics of a $\mathrm{Ti}-7.4$ at $\% \mathrm{Al}$ alloy at low temperatures. Data from present tests and from Refs. (1), (4) and (14).

Furthermore, it can be shown that ${ }^{(11)}$

$$
M V=\frac{3}{2} b x^{*} l^{*}
$$

where $x^{*}$ is the activation distance. Inserting the Friedel relation for $l^{*}$ into eq. (16) gives

$$
x^{*}=\frac{3}{2} M V\left(\tau^{*} C_{i} / 2 \mu\right)^{1 / 3}
$$

The force-activation distance curve derived from the present data on the $\mathrm{Ti}-7.4$ at $\% \mathrm{Al}$ alloy using eqs. (15) and (17) and taking $M=5$ is shown in Fig. 13. Also included are the average curve for unalloyed titanium $^{(4)}$ and values derived from the data of Zeyfang and Conrad on the Ti-15.2 at \%Mo-alloy(14). It is seen from the figure that there is a good agreement between the results for the Ti-7.4 at \% Al and the average curve for unalloyed titanium. It is thus concluded that the rate controlling mechanism in the $\mathrm{Ti}-\mathrm{Al}$ alloy is similar to that of unalloyed c.p.h. titanium, namely thermally activated overcoming of interstitial solute atoms. The increase in strength of titanium due to the aluminium substitutional solute atoms and grain size variation is principally through the athermal component of the flow stress.

\section{Acknowledgment}

One of the authors (H.C.) wishes to acknowledge partial support for this investigation by the Air Force Materials Laboratory under contract AF 33615-68C-1052, Dr. H. Gegel, technical monitor.

\section{REFERENCES}

(1) K. Okazaki, T. Itoh and H. Conrad: submitted to Acta Met.

(2) G. A. Sargent and H. Conrad: Scripta Met., 4 (1970). 129.

(3) H. Conrad, K. Okazaki, V. Gadjil and M. Jon: Electron Microscopy and Structure of Materials, Univ. of Calif. 
Press, Berkerley, (1972), p. 438.

(4) K. Okazaki and H. Conrad: Acta Met., 21 (1973), 1117.

(5) H. Conrad: Acta Met., 7 (1966), 1631.

(6) P. Ganesan, K. Okazaki and H. Conrad: in preparation.

(7) K. Okazaki and H. Conrad: Met. Trans., 3 (1972), 2411.

(8) H. Conrad, M.Doner and B. de Meester: Titanium Science and Technology, The Met. Soc. of AIME Proceedings, Plenum Press, N.Y. (1973), p. 969.

(9) E. S. Fisher and G. J. Renken: Phys. Rev., 135, No. 2A, (1964), A482.

(10) R. L. Jones, F. W. Cooke, H. Conrad and B. R. Bernerjee: Investigations to Understand the Deformation and Strength- ening Mechanism of Solid Solution Phases of Titanium, Tech. Rept. AFML-TR-68-28 (Feb. 1968).

(11) B. de Meester, C. Yin, M. Doner and H. Conrad: Thermally Activated Deformation of Crystalline Solids, to be published John E. Dorn Memo. Symp. Rate Processes in Plastic Deformation, Cleveland, Ohio, Oct. 16-17, (1972).

(12) J. Friedel: Dislocations, Addison-Wesley, Reading, Mass., (1965), p. 224.

(13) W. R. Tyson and G. B. Craig: Canad. Met. Quarterly, 7 (1968), 119.

(14) R. Zeyfang and H. Conrad: Acta Met., 19 (1971), 985. 